\title{
Experimental Study of Adaptive Sliding Mode Control for Vibration of a Flexible Rectangular Plate
}

\author{
Jingyu Yang*, Zhiqi Liu, Xuanming Cui, Shiying Qu and Chu Wang \\ Joint Laboratory of Spacecraft Dynamics and Control, Faculty of Aerospace Engineering, Shenyang Aerospace \\ University, Shenyang 110136, China
}

\section{Zhou Lanwei and Guoping Chen}

The State Key Laboratory of Mechanics and Control for Mechanical Structures, Nanjing University of Aeronautics and Astronautics, Nanjing 210016, China

\begin{abstract}
This paper aims to address the intelligent active vibration control problem of a flexible rectangular plate vibration involving parameter variation and external disturbance. An adaptive sliding mode (ASM) MIMO control strategy and smart piezoelectric materials are proposed as a solution, where the controller design can deal with problems of an external disturbance and parametric uncertainty in system. Compared with the current 'classical' control design, the proposed ASM MIMO control strategy design has two advantages. First, unlike existing classical control algorithms, where only low intelligence of the vibration control system is achieved, this paper shows that high intelligent of the vibration control system can be realized by the ASM MIMO control strategy and smart piezoelectric materials. Second, the system performance is improved due to two additional terms obtained in the active vibration control system. Detailed design principle and rigorous stability analysis are provided. Finally, experiments and simulations were used to verify the effectiveness of the proposed strategy using a hardware prototype based on NI instruments, a MATLAB/SIMULINK platform, and smart piezoelectric materials.
\end{abstract}

Key words: Plate Vibration, Active Control, ASM MIMO Controller, Intelligent Experimental ASM MIMO Control System, Smart Piezoelectric Materials

\section{Introduction}

Typically, modern spacecraft include some flexible structures, such as solar arrays and antennas. Attitude maneuvers are prone to excite vibrations in these flexible structures because of their typically low damping. Such vibrations have characteristics of large amplitudes and long periods of time. Moreover, the coupling between elastic and rigid-body motions can be aroused during the orientation of a spacecraft. As a result, the issues of dynamic modeling and vibration control of flexible spacecraft structures have been studied intensively recently.

Literature reviews on active vibration control of flexible structures have been presented in several investigations. The development of active vibration control experienced two stages: 'classical' active vibration control and intelligent active vibration control.

With respect to classical active vibration control, Dixiong Yang (1) revealed the essential connections among several popular chaos feedback control approaches, investigated the intrinsic relationship between the stability transformation method and speed feedback control method for controlling the equilibrium of continuous autonomous systems. Danfeng (2) applied a harmonic balance method to investigate the amplitude of the self-excited vibration, and designed a PI controller to control the amplitude of the vibration at a

This is an Open Access article distributed under the terms of the Creative Commons Attribution Non-Commercial License (http://creativecommons.org/licenses/by$\mathrm{nc} / 3.0 /$ ) which permits unrestricted non-commercial use, distribution, and reproduction in any medium, provided the original work is properly cited. 
given level. The effectiveness of this method showed good prospects for its application to commercial maglev systems. Bin (3) proposed a non linear dynamic modeling method for a rigid-flexible coupling satellite antenna system composed of laminated shell reflector undergoing a large overall motion, and used a PD with a vibration force feedback control strategy to eliminate the system vibration. Previdi (4) presented a full analysis and the complete development of a system for mechanical vibration reduction in a kitchen hood using piezoelectric actuators, and provided a minimum variance (MV) controller to get the theoretically 'best' performance in terms of noise reduction. Xiuting (5) investigated the potential beneficial performance of a quasi-zero-stiffness vibration isolator (QZS-VI) with a simple linear time-delayed active control strategy, provide a time-delayed active control which can not only further strengthen the robustness of the system in stability, but also noticeably improved system transmissibility performance both in force and base excitations and obviously decrease the settling time of system transient response subject to an impact load. Dafang (6) investigated active vibration control of a flexible beam with piezoelectric pieces on the surface using an independent modal space control method, which was able to control the first three modes of the beam independently. Cazzulani (7) proposed exploiting the measurements of Fiber Bragg Grating sensors as feedback for active vibration control applications. The experimental tests confirmed that smart structures with embedded FBG sensors could be profitably designed to suppress vibrations. $\mathrm{Hu}(8)$ presented a new and effective approach for vibration suppression of large space structures, and developed the equations of motion of a flexible structure with a set of arbitrarily distributed CMGs. Xianglong (9) presented an analytical study of active structural acoustic control of an elastic cylindrical shell coupled to a two-stage vibration isolation system, and developed an analytical activepassive model to attenuate sound radiating from the base shell structure, which consisted of a rigid-body machine, an intermediate rigid mass, and a supporting cylindrical shell, all connected by a combination of passive and active isolators.

Regarding intelligent active vibration control research, using robust control theory, Zhang (10) investigated the robust finite frequency $H_{\infty}$ passive fault-tolerant staticoutput-feedback controller design problem, used the finite frequency $H_{\infty}$ control to attenuate the effect from the external disturbance to the controlled output. Zhicheng (11) developed an active vibration control for a two-hinged plate, obtained state space representations for bending and torsional vibrations, and designed two $H_{\infty}$ robust controllers for suppressing the vibrations of the bending and torsional modes, based on two low-order models of the bending and torsional motion.

Using adaptive control theory and fuzzy control theory, Zolfagharian (12) presented a mechatronic approach integrating both passive and active controllers to deal with unwanted noise and vibration produced in an automobile wiper system operation; a bi-level adaptive-fuzzy controller was used where the parameters were tuned simultaneously by a multi-objective genetic algorithm (MOGA) to deal with the conflicting interests in the wiper control problem. Jaroslaw (13) presented a fuzzy logic-based robust feedback anti-sway control system that could be applicable with or without a sensor of sway angle of a payload, and proposed an iterative procedure combining a pole placement method and interval analysis of closed-loop characteristic polynomial coefficients to design a robust control scheme. Nemanja (14) dealt with active free vibration control of smart composite beams using a particle-swarm optimized self-tuning fuzzy logic controller, and proposed integration of a self-tuning method with membership function optimization using the PSO algorithm to improve FLC performance and robustness.

Young presented the concept of sliding mode control in 1978, since when it has been used by many researchers in the field of engineering control. However, few papers talked about AVC of flexible structures using the sliding mode control algorithm. A. El et al. (15) presented a nonlinear controller design for biaxial feed drive systems for reducing the control input variance while maintaining motion accuracy. Experimental results demonstrated a significant performance improvement in terms of control input variance while maintaining motion accuracy. Oliveira et al. (16) presented an automatic tuning method for the discontinuous component of the Sliding Mode Generalized Predictive Controller (SMGPC), subject to constraints. Simulations and performance indexes for common process models in industry, such as non-minimum phase and timedelayed systems, resulted in better performance, improving robustness and tracking accuracy. Chen et al. (17) proposed an intelligent self-repairing control scheme for a class of nonlinear MIMO systems; the control method was applied to a helicopter flight control system with loss-in-effectiveness faults. Some simulation results illustrated the effectiveness and feasibility of the proposed control scheme in the paper. Ghasemi et al. (18) used the notion of finite-time stability to apply it to the problem of coordinated motion in multi-agent systems, obtained non-Lipschitzian closed-loop dynamics restricted to the surface, which leads to the convergence of the system trajectories to the origin in finite time. Acosta et al. (19) introduced a sliding mode control approach for 
designing multiple discontinuous control inputs, where the control effort overcame only uncertainties, disturbances or unstable dynamics. Two illustrative examples were given to show the feasibility of the method. Zhang et al. (20) proposed a fractional order sliding mode control (FROSMC) scheme for the velocity control of permanent magnet synchronous motor (PMSM), and used a fuzzy logic inference scheme (FLIS) to obtain the gain of switching control. Simulations and experiments demonstrated that the proposed FROSMC not only achieved better control performance with smaller chatting than that with integer order sliding mode control, but it was also robust to external load disturbance and parameter variations. Zhang et al. (21) exploited the robust $H_{\infty}$ sliding-mode controller design problem for discretetime Markovian jump linear systems, and provided two numerical examples to illustrate the advantages and the efficacy of the proposed method when simultaneously considering intermittent observations, system uncertainty, and external disturbance. In 2014, Yang et al. (22) presented an experimental study about flexible plate using adaptive fuzzy sliding mode (AFSM) control strategy; however, the limitations of above control strategy were more complex and it was difficult to be applied in control engineering, so there is still s need to investigate vibration control using other intelligent control methods. Then, the advantages of different control strategies could be compared. Surely, the feasibility of control algorithms in engineering practice would be confirmed.

The proposed ASM MIMO control scheme can be used in active vibration control systems in which unknown disturbances and perturbations increase the complexity of a non-linear complex vibration system. Thus, the intelligent controller design becomes more challenging. Moreover, the proposed scheme incorporates an adaptive control law mechanism to deal with uncertainty. To achieve better tracking vibration control performance in a limited time and to attenuate efficiently the effects of both disturbances and uncertainties to an expectation level, an ASM MIMO control scheme was adopted in the control design for a structure vibration control system with parameter uncertainties. Finally, experiments and numerical simulation examples of a flexible plate structure vibration system are provided to confirm the effectiveness of the proposed intelligent vibration control scheme.

\section{Dynamics Model of Flexible Plate}

In this section, the present discretization and reducedorder modeling method (DROMM) for modeling of a flexible plate structure will be considered. The proposed method achieves an accurate dynamics model and its structure is simple, thereby providing controller design with MIMO features, and the effectiveness of the vibration control system can maintain the vibration reduction performance based on intelligent control theory.

Considering the continuous cantilever plate (Fig. 1) and discrete state of the plate (Fig. 2) (22), we can establish a dynamic model of the rectangular plate

$$
[M][\ddot{Y}]+\left[P+\Delta P\left(L_{0}, \ddot{Y}, \dot{Y}, Y\right)\right][\dot{Y}]+\left[K+\Delta K\left(L_{0}, \ddot{Y}, \dot{Y}, Y\right)\right][Y]=[L][F]
$$
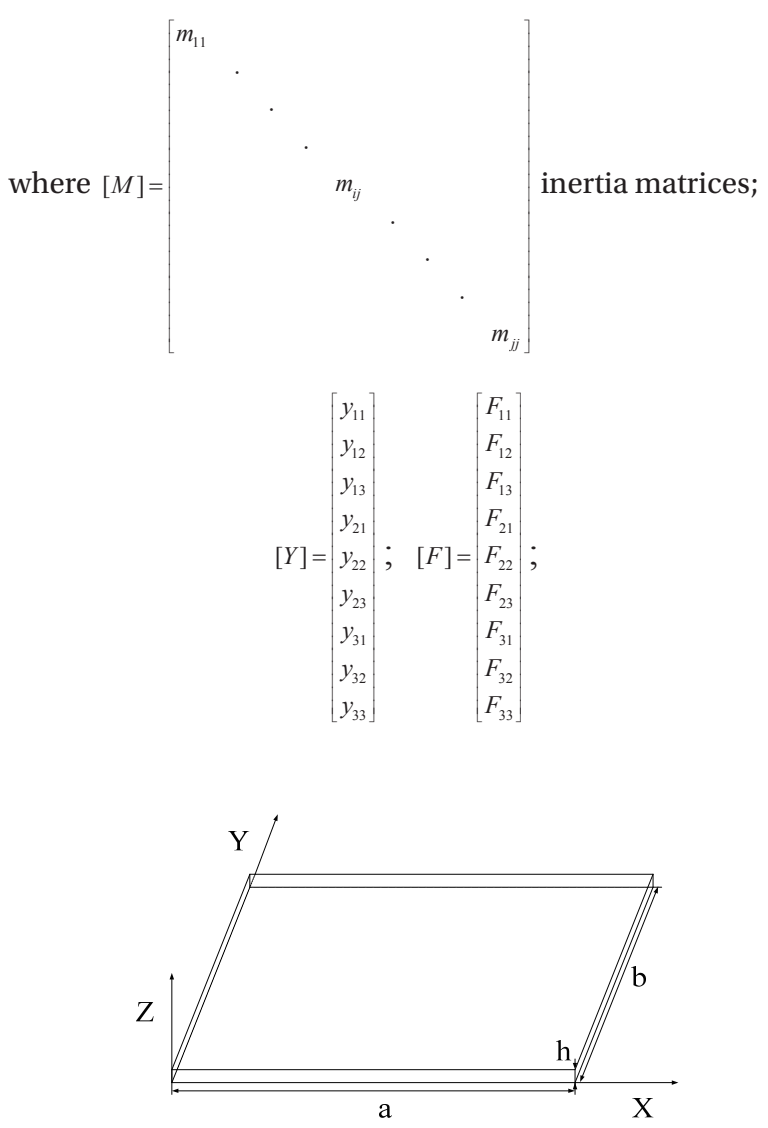

Fig. 1. Cantilever plate

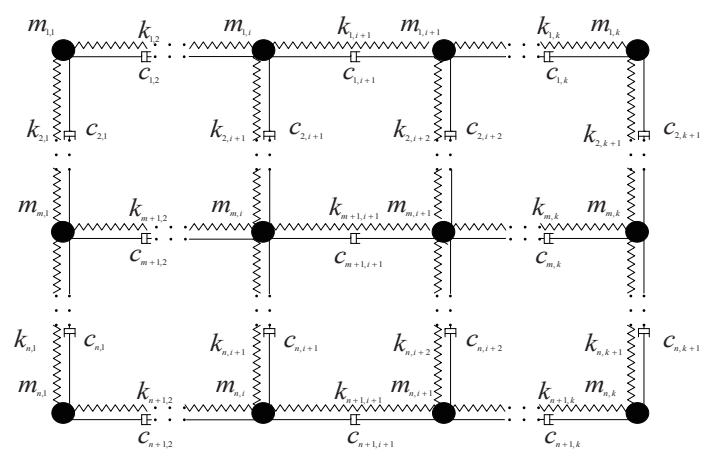

Fig. 2. The discrete cantilever plate 


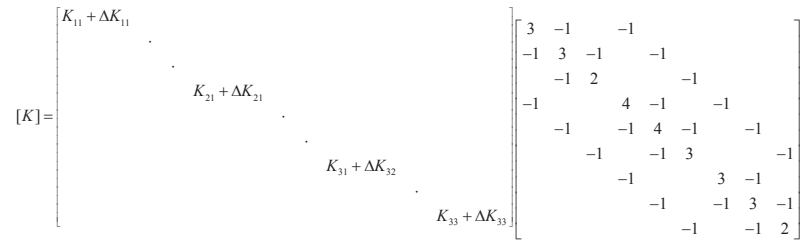

stiffness matrices; $\Delta K_{i j}=\Delta K_{i j}\left(L_{0}, \ddot{Y}_{i j}, \dot{Y}_{i j}, Y_{i j}\right)$ where $i, j=1,2,3$

Assumed that:

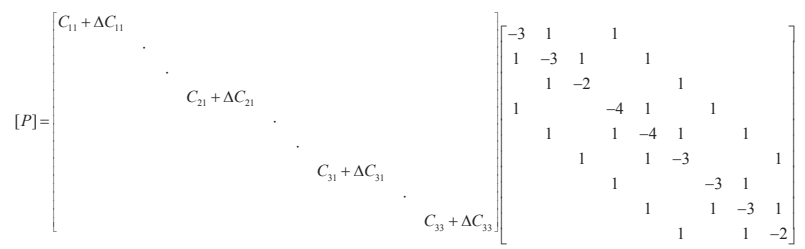

damping matrices; $\Delta C_{i j}=\Delta C_{i j}\left(L_{0}, \ddot{Y}_{i j}, \dot{Y}_{i j}, Y_{i j}\right)$ where $j, i=1,2,3$, $U$ is the $s \times 1$ input vector; $X$ is the $n_{d} \times 1$ nodal displacement vector; $\ddot{X}$ is the $n_{d} \times 1$ nodal velocity vector; $\ddot{X}$ is the $n_{d} \times 1$ nodal acceleration vector; $[P]$ is the damping matrix, $n_{d} \times n_{d}$; $[M]$ is the mass matrix, $n_{d} \times n_{d} ; F_{i j}$ is a concentrated force that is applied to $m_{i j}$; $[K]$ is the stiffness matrix, $n_{d} \times n_{d}$; and $[L]$ is influence coefficient matrix, $n_{d} \times s$.

\section{Example of Flexible Plate Modeling}

An example is used for illustration. The plate is $10 \mathrm{~m} \times 10$ $\mathrm{m}$, the elasticity modulus $E=206 \mathrm{GPa}$, Poisson's ratio $=0.3$, $\rho=7900 \mathrm{~kg} / \mathrm{m}$, the elasticity shear modulus $G=79.4 \mathrm{GPa}$, and the thickness is $0.001 \mathrm{~m}$. Using the dynamics modeling method above, the parameters of the model $([\mathrm{M}],[\mathrm{K}],[\mathrm{P}],[\mathrm{L}])$ can be obtained.

Paper (23) confirmed the validity of the new model obtained by comparing essential features between a finite element model and obtained model, such as natural frequencies.

\section{The Design of Asm Mimo Controller}

An $n$ degree of freedom plate system (24) model is described as

$$
\hat{M}(q) \ddot{q}_{r}+\hat{C}(q, \dot{q}) \dot{q}_{r}+\hat{K}(q)=\tau
$$

where $q$ is the $n \times 1$ vector of nodal displacements, $\tau$ is the $n \times 1$ vector of applied nodal forces, $\hat{M}(q)$ is the $n \times n$ symmetric positive definite manipulator inertia matrix, $\hat{C}(q, \dot{q}) \dot{q}$ is the $n \times 1$ vector of damping forces, and $\hat{K}(q)$ is the $n \times 1$ vector of elastic forces.

The controller design problem is as follows. Given the desired trajectory $q_{d}(t)$, and with some or all the rectangular plate system parameters being unknown, derive a control law for the actuator forces and an estimation law for the unknown parameters such that the rectangular plate system output $q(t)$ tracks the desired trajectories after an initial adaptation process.

Undesirable steady-state position errors can be eliminated if we restrict them to lie on a sliding surface

$$
\dot{\tilde{q}}+\Lambda \tilde{q}=0
$$

where $\Lambda$ is a constant matrix, whose eigenvalues are strictly in the right-half complex plane. Formally, we achieve this by replacing the desired trajectory $q_{d}(t)$ in the above derivation by the virtual "reference trajectory."

$$
q_{r}=q_{d}-\Lambda \int_{0}^{t} \tilde{q} d t
$$

Accordingly, $\dot{q}_{d}$ and $\ddot{q}_{d}$ are replaced by

$\dot{q}_{r}=\dot{q}_{d}-\Lambda \tilde{q} ; \ddot{q}_{r}=\ddot{q}_{d}-\Lambda \dot{\tilde{q}}$

If we define the sliding surface

$$
s=\dot{\tilde{q}}_{r}=\dot{q}-\dot{q}_{r}=\dot{\tilde{q}}+\Lambda \tilde{q}
$$

The control law and adaptation law become

$$
\begin{aligned}
& \tau=\hat{M}(q) \ddot{q}_{r}+\hat{C}(q, \dot{q}) \dot{q}_{r}+\hat{K}(q)-K_{D} s \\
& \dot{\hat{a}}=-\Gamma^{-1} Y^{T}\left(q, \dot{q}, \dot{q}_{r}, \ddot{q}_{r}\right) s
\end{aligned}
$$

Note that the matrix $Y(25)$ is now a function of $\ddot{q}_{r}$ and $\dot{q}_{r}$, rather than $\ddot{q}_{d}$ and $\dot{q}_{d}$. We can again demonstrate global convergence of the tracking by now using the Lyapunov function

$$
\begin{aligned}
& V(t)=\frac{1}{2} s^{T} M s+\frac{1}{2} \tilde{a}^{T} M \tilde{a} \\
& \dot{V}(t)=s^{T}\left(\tau-C\left(s+\dot{q}_{r}\right)-G-M \ddot{q}_{r}\right)+\frac{1}{2} s^{T} \dot{M} s+\tilde{a}^{T} \Gamma \dot{\tilde{a}}
\end{aligned}
$$

Considering the equation $\tilde{M}(q) \ddot{q}_{d}+\tilde{C}(q, \dot{q}) \dot{q}_{d}+\tilde{K}(q)=Y \tilde{a}(26)$.

$$
\dot{V}(t)=\tilde{a}^{T}\left(Y^{T} s+\Gamma \dot{\tilde{a}}\right)-s^{T} K_{D} s-s^{T} C s=-s^{T}\left[K_{D}+C\right] s \leq 0
$$

Note that control law (8) does not contain a term in, because the position error $\tilde{q}$ is already included in $\dot{\tilde{q}}_{r}$. Expression (10) shows that the output errors converge to the sliding surface

$$
s=\dot{\tilde{q}}+\Lambda \tilde{q}=0
$$

This, in turn, implies that $\tilde{q} \rightarrow 0$ as $t \rightarrow \infty$. Thus, the adaptive controller defined by (8) is globally asymptotically stable and guarantees zero steady-state error for node positions. 


\section{Numerical example}

Letting $\hat{M}=[M], \quad \hat{C}(q, \dot{q})=[P], \quad[K][Y]=K(q), \quad \tau=[L][F]$, $\Phi\left(q, \dot{q}_{r}, \dot{q}, \ddot{q}_{r}\right)=[L]$,

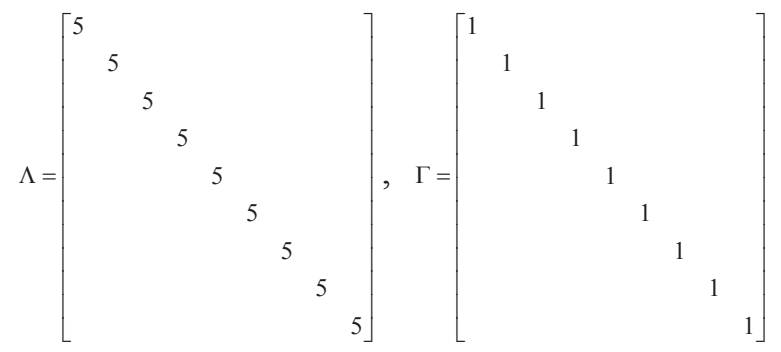

$K_{D}=\left[\begin{array}{lllllllll}100 & & & & & & & & \\ & 100 & & & & & & & \\ & & 100 & & & & & & \\ & & & 100 & & & & & \\ & & & & 100 & & & & \\ & & & & & 100 & & & \\ & & & & & & 100 & & \\ & & & & & & & 100 & \\ & & & & & & & & 100\end{array}\right]$.
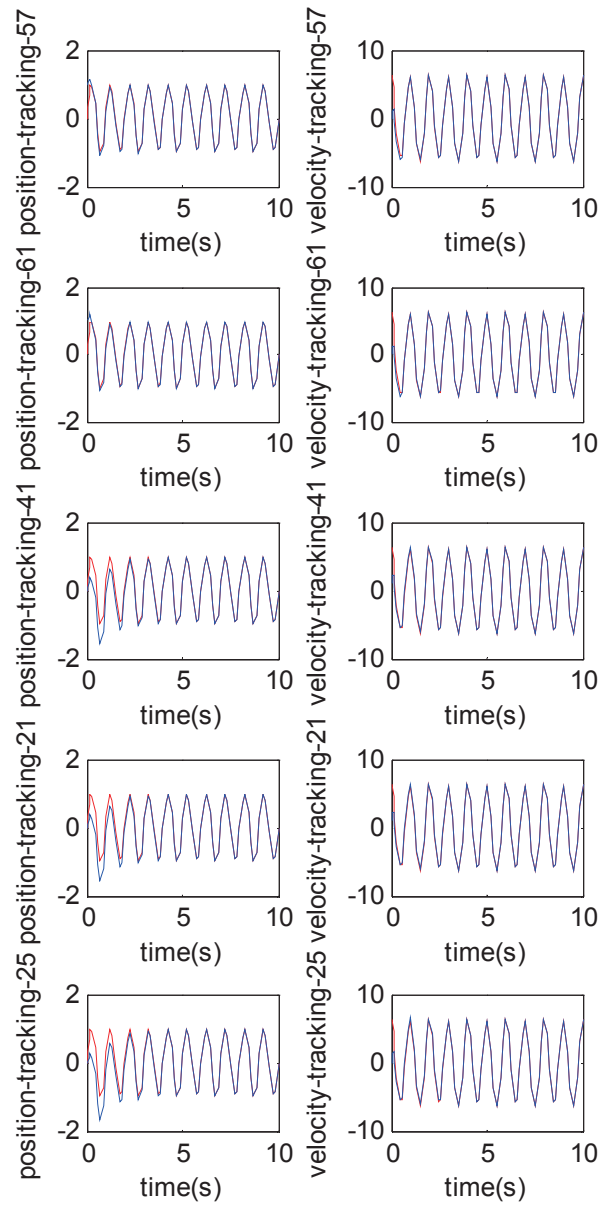

The desired joint trajectory is given by q1_d=sin(2Пt); q2_d=sin(2חt); q3_d=sin(2חt); q4_d=sin(2חt); q5_d=sin(2חt); q6_d=sin(2חt); q7_d=sin(2Пt); q8_d=sin(2Пt); q9_d=sin(2Пt);

The displacements and velocities are chosen as $x=\left[\begin{array}{llllllllllllllllll}y_{1} & \dot{y}_{1} & y_{2} & \dot{y}_{2} & y_{3} & \dot{y}_{3} & y_{4} & \dot{y}_{4} & y_{5} & \dot{y}_{5} & y_{6} & \dot{y}_{6} & y_{7} & \dot{y}_{7} & y_{8} & \dot{y}_{8} & y_{9} & \dot{y}_{9}\end{array}\right]$ The initial displacements and velocities are chosen as $\mathrm{x}_{0}=[1.0,0,1.0,0,1.0,0,1.0,0,1.0,0,1.0,0,1.0,0,1.0,0,1.0,0]$;

Using control law (8), Fig. 3 shows the ASM MIMO control of the $57^{\text {th }}, 59^{\text {th }}, 61^{\text {st }}, 39^{\text {th }}, 41^{\text {st }}, 43^{\text {rd }}, 21^{\text {st }}, 23^{\text {rd }}$, and $25^{\text {th }}$ nodes. Fig. 4 shows PD position tracking control of $57^{\text {th }}, 59^{\text {th }}, 61^{\text {st }}$, $39^{\text {th }}, 41^{\text {st }}, 43^{\text {rd }}, 21^{\text {st }}, 23^{\text {rd }}$, and $25^{\text {th }}$ nodes.

In this section, the effectiveness of ASM MIMO control is examined with the new plant model. Comparison of vibration response tracking control during the simulation time, and vibration control for the flexible plate vibration system is discussed on the basis of the intelligent control scheme shown in Figs. 3 and 4. When conducting active suppression of the vibration, nine points are preferably chosen as the tracking signal. From Figs. 3 and 4, the vibration response tracking control at each point is not
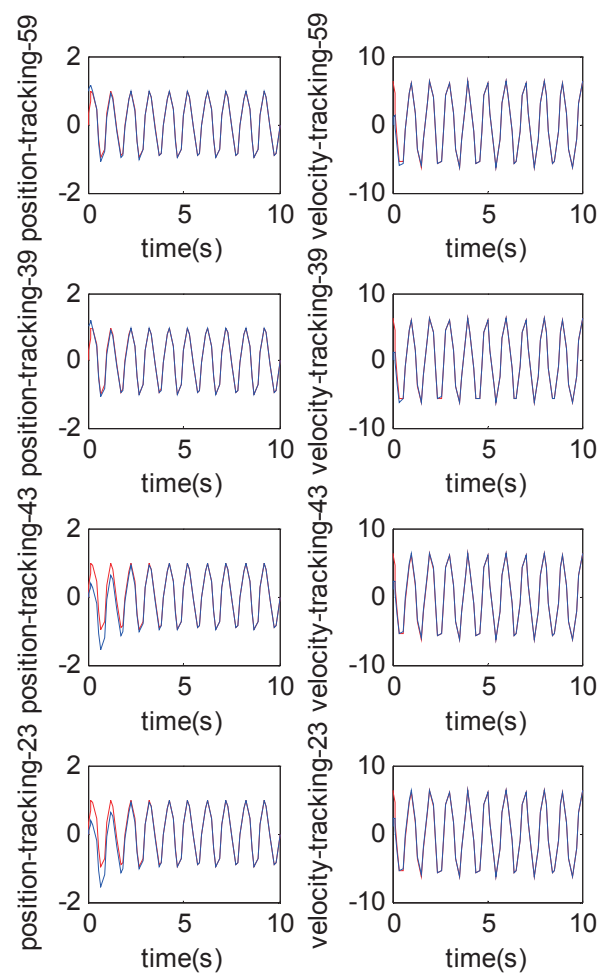

Fig. 3. Position tracking of the $57^{\text {th }}, 59^{\text {th }}, 61^{\text {st }}, 39^{\text {th }}, 41^{\text {st }}, 43^{\text {rd }}, 21^{\text {st }}, 23^{\text {rd }}$, and $25^{\text {th }}$ nodes. Unit: $\mathrm{m}$. 

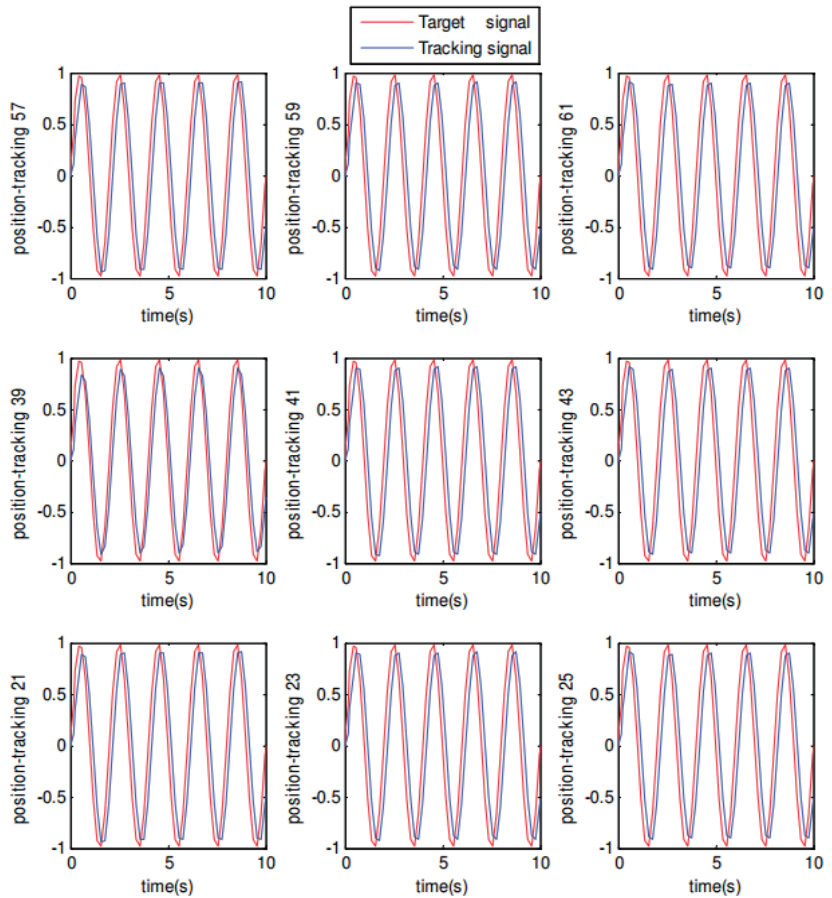

Fig. 4. PD position tracking error of $57^{\text {th }}, 59^{\text {th }}, 61^{\text {st }}, 39^{\text {th }}, 41^{\text {st }}, 43^{\text {rd }}, 21^{\text {st }}, 23^{\text {rd }}$, and $25^{\text {th }}$ nodes.

good when the PD control method is adopted. In contrast, numerical simulation results of the proposed ASM MIMO control algorithm behavior are very good, especially when there are some disturbances in the system.

\section{Experimental study with smart piezoelectric materials}

\section{FEA calculation and contrast analysis}

These results are shown in Table 1 and Figs. 5-7.

It is easy to see that there are small difference between the frequency of the PZT plate and the frequency of the regular plate.

\section{Model test results and contrast analysis}

This section presents the results obtained on the test- flexible plate. The plate is composed of several segments, as shown in Figs. 8-10. Table 2 shows the experimental results of natural frequency, obtained from different model test methods. We can see that data of Groups 7 and 8 are better than the other groups. In particular, we can see that the data

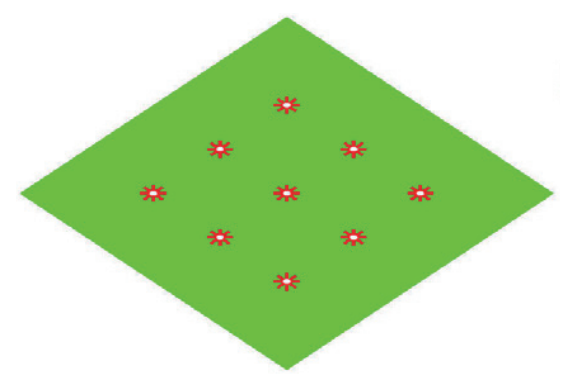

Fig. 5. PZT plate

Table 1. Contrastive analysis results

\begin{tabular}{|c|c|c|c|c|c|c|c|c|c|}
\hline $\begin{array}{c}\text { Natural } \\
\text { Frequency }\end{array}$ & 1 & 2 & 3 & 4 & 5 & 6 & 7 & 8 & 9 \\
\hline $\begin{array}{c}\text { FEA result } \\
\text { (Regular } \\
\text { plate) }\end{array}$ & 0.8359 & 2.027 & 5.0545 & 6.3662 & 7.2835 & 12.459 & 14.451 & 14.669 & 16.525 \\
\hline $\begin{array}{c}\text { FEA result } \\
\text { Piezoelectric } \\
\text { plate) }\end{array}$ & 0.8392 & 2.0547 & 5.1419 & 6.5629 & 7.4702 & 13.05 & 14.792 & 15.453 & 17.111 \\
\hline $\begin{array}{c}\text { Absolute } \\
\text { error }\end{array}$ & 0.0033 & 0.0277 & 0.0874 & 0.1967 & 0.1867 & 0.591 & 0.341 & 0.784 & 0.586 \\
\hline
\end{tabular}


of Groups 7 and 8 are in agreement with the results of the numerical simulation. Additionally, the results of flexible cantilever plate structure with nine PZT patches are shown in Table 3.

Optimal piezoelectric actuator locations and orientations

An intelligent optimal algorithm design method is presented for the orientation, placement, and numbers of actuators and sensors in closed-loop intelligent vibration control systems (Fig. 10). The method can be used to develop the non-linear programming problem; it is efficient and can handle complex optimization

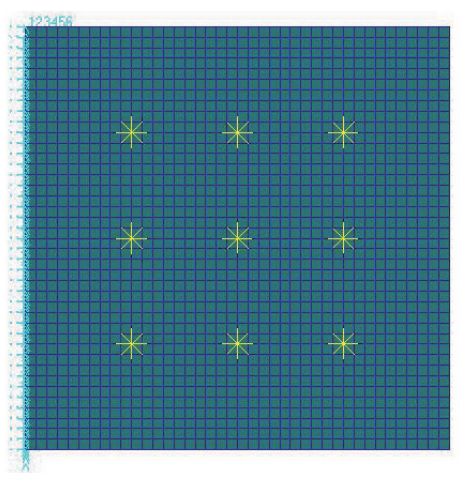

Fig. 6. PZT plate FEA model

Table 2. Modal test value of natural frequency before installed actuators/sensors

\begin{tabular}{|c|c|c|c|c|c|c|c|c|c|c|c|}
\hline Location & Method & & 1 & 2 & 3 & 4 & 5 & 6 & 7 & 8 & 9 \\
\hline \multirow{13}{*}{ A } & \multirow{4}{*}{ Random } & $\begin{array}{c}\text { Group } \\
1\end{array}$ & & 2.8 & 6.9 & 7.4 & 10.6 & 15.2 & 17.3 & 21.6 & 25.2 \\
\hline & & $\begin{array}{c}\text { Group } \\
2\end{array}$ & & 2.8 & 7 & 10.5 & 15 & 17.3 & 21.8 & 25.3 & 28.3 \\
\hline & & $\begin{array}{c}\text { Group } \\
3\end{array}$ & & 2.6 & 7.1 & 10.5 & 15.1 & 17.3 & 21.8 & 25.3 & 26.4 \\
\hline & & $\begin{array}{c}\text { Group } \\
4\end{array}$ & & 7.2 & 10.6 & 15.2 & 16.9 & 21.7 & 25.3 & 28.3 & 34.1 \\
\hline & \multirow{8}{*}{$\begin{array}{c}\text { Sine } \\
\text { Sweep }\end{array}$} & $\begin{array}{c}\text { Group } \\
1\end{array}$ & 0.8 & 2.6 & 4.1 & 7.4 & 10.7 & 13.1 & 15.2 & 17.3 & 21.8 \\
\hline & & $\begin{array}{c}\text { Group } \\
2\end{array}$ & 0.8 & 2.6 & 4.9 & 7.7 & 10.7 & 13.1 & 15.2 & 17.3 & 21.8 \\
\hline & & $\begin{array}{c}\text { Group } \\
3\end{array}$ & 0.8 & 2.6 & 4.1 & 7.4 & 10.7 & 13.1 & 15.2 & 17.2 & 21.8 \\
\hline & & $\begin{array}{c}\text { Group } \\
4\end{array}$ & 0.8 & 2.6 & 4.1 & 7.4 & 10.7 & 13.1 & 15.2 & 17.2 & 21.8 \\
\hline & & $\begin{array}{c}\text { Group } \\
5\end{array}$ & 0.8 & 2.6 & 4.4 & 5.2 & 6.9 & 7.5 & 10.8 & 12.9 & 15.2 \\
\hline & & $\begin{array}{c}\text { Group } \\
6\end{array}$ & 0.8 & 2.8 & 4.4 & 5.2 & 6.9 & 7.8 & 10.7 & 13.0 & 15.2 \\
\hline & & $\begin{array}{c}\text { Group } \\
7\end{array}$ & 0.7 & 2.8 & 4.0 & 5.3 & 6.9 & 7.6 & 8.8 & 10.6 & 13.2 \\
\hline & & $\begin{array}{c}\text { Group } \\
8\end{array}$ & 0.7 & 2.8 & 4.0 & 5.3 & 6.9 & 7.6 & 8.8 & 10.6 & 13.2 \\
\hline & $\begin{array}{l}\text { Hammer } \\
\text { Shot }\end{array}$ & \multicolumn{10}{|c|}{ Failure } \\
\hline \multirow{6}{*}{ B } & \multirow{3}{*}{ Random } & $\begin{array}{c}\text { Group } \\
1\end{array}$ & & 2.6 & 3.9 & 6.8 & 7.4 & 10.8 & 12.9 & 15.3 & 17.1 \\
\hline & & $\begin{array}{c}\text { Group } \\
2\end{array}$ & & 2.8 & 3.9 & 6.8 & 7.4 & 10.6 & 12.9 & 16.6 & 17.1 \\
\hline & & $\begin{array}{c}\text { Group } \\
3 \\
\end{array}$ & & 2.8 & 4 & 6.9 & 7.5 & 10.8 & 12.9 & 15.3 & 17.1 \\
\hline & \multirow{2}{*}{$\begin{array}{c}\text { Sine } \\
\text { Sweep }\end{array}$} & $\begin{array}{c}\text { Group } \\
1\end{array}$ & 0.7 & 2.7 & 3.9 & 6.7 & 7.4 & 8.6 & 10.5 & 13.0 & 15.2 \\
\hline & & $\begin{array}{c}\text { Group } \\
2 \\
\end{array}$ & 0.7 & 2.7 & 3.9 & 6.7 & 7.4 & 8.6 & 10.5 & 13.0 & 15.2 \\
\hline & $\begin{array}{c}\text { Hammer } \\
\text { Shot }\end{array}$ & \multicolumn{10}{|c|}{ Failure } \\
\hline
\end{tabular}


problems and deal with many optimization variables. Several numerical analysis results $(27,28)$ were performed to confirm the effectiveness of the method. Multiple procedures for the scheme are possible for the multi- objective optimization problem, and generated a set of solutions that can be used to configure the number and the actuators's orientations and locations. This is illustrated in the example.

Table 3. Model test values of natural frequency

\begin{tabular}{|l|l|l|l|l|l|l|l|l|l|l|}
\hline Frequency & & 1 & 2 & 3 & 4 & 5 & 6 & 7 & 8 & 9 \\
\hline \multirow{3}{*}{ Experiment } & Group 1 & 0.7 & 2.8 & 4.0 & 5.3 & 6.9 & 7.6 & 8.8 & 10.6 & 13.2 \\
\cline { 2 - 12 } & Group 2 & 0.7 & 2.7 & 3.9 & & 6.7 & 7.4 & 8.6 & 10.5 & 13.0 \\
\cline { 2 - 11 } & Average & 0.7 & 2.75 & 3.95 & 5.30 & 6.8 & 7.5 & 8.7 & 10.55 & 13.1 \\
\hline FEM & Group 1 & 0.84 & 2.03 & & 5.05 & 6.37 & 7.28 & 12.46 & 14.451 & 14.67 \\
\hline & Error & 0.14 & 0.72 & & 0.25 & 0.43 & 0.22 & 3.76 & 3.901 & 1.57 \\
\hline
\end{tabular}

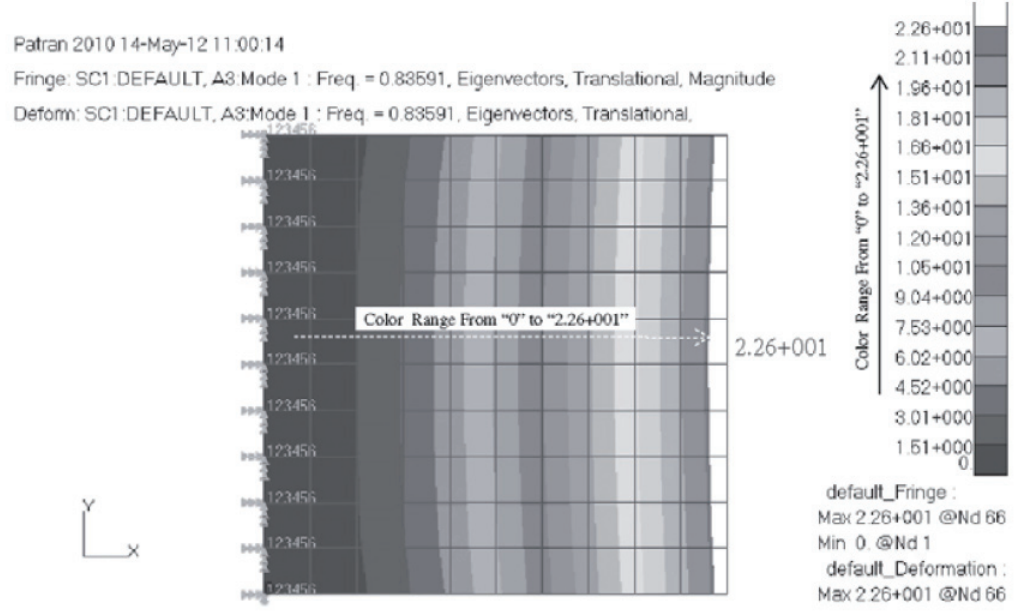

(a)

Patran 2010 18-Feb-14 09:56:17

Fringe: Default, A1:Mode $1:$ Freq. $=0.83929$. Eigenvectors. Translational, Magnitude, (NON-LAYERED)

Deform: Default, A1:Mode $1:$ Freq. = 0.83929, Eigenvectors, Translational,
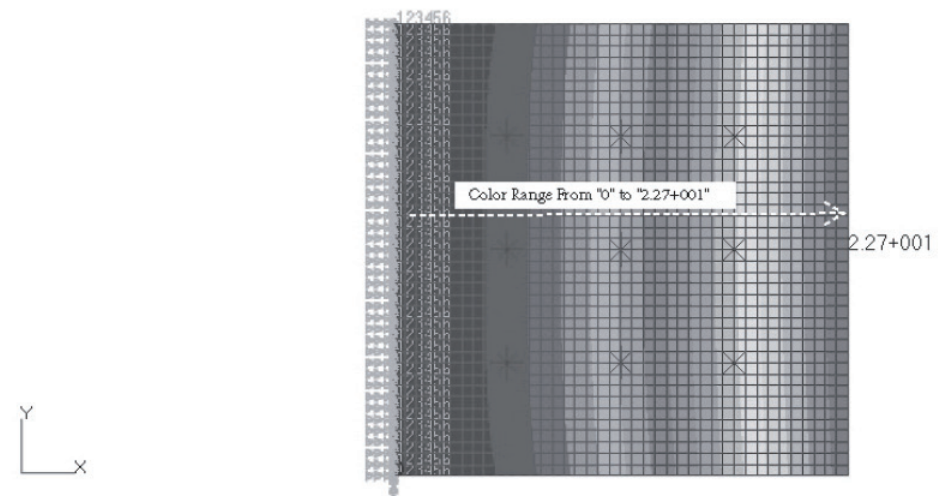

(b)

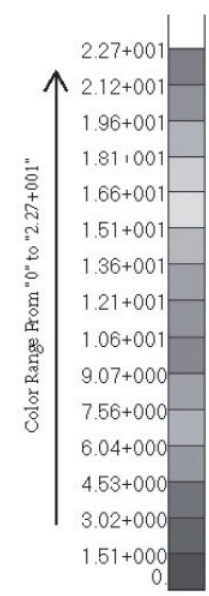

default_Fringe Max227+001@Nd 777 Min 0.@Nd 2397 default_Deformation : Max2.27+001@Nd 777

Fig. 7. Contrastive analysis of the first mode shape between common FEA model and PZT plate FEA model. (a) Common plate FEA model (b) PZT plate FEA model 


\section{Mechanical-electric coupled model}

The procedure of a new modeling method is discussed in this section, and the parameters of dynamic Eq. (3) are

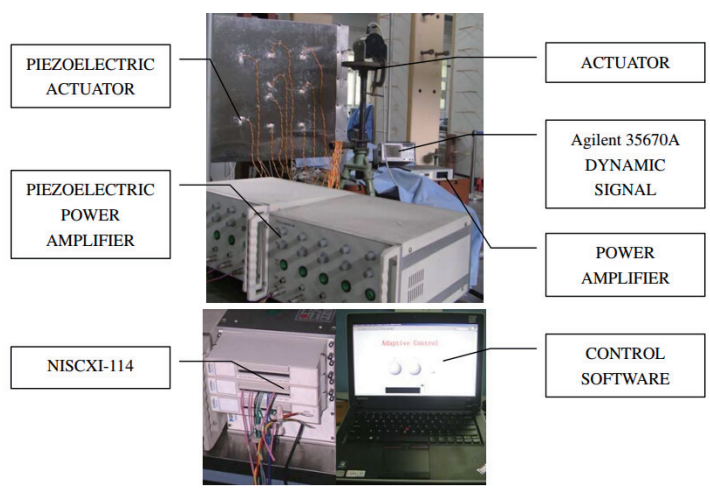

Fig. 8. Experiment and control instruments (1)

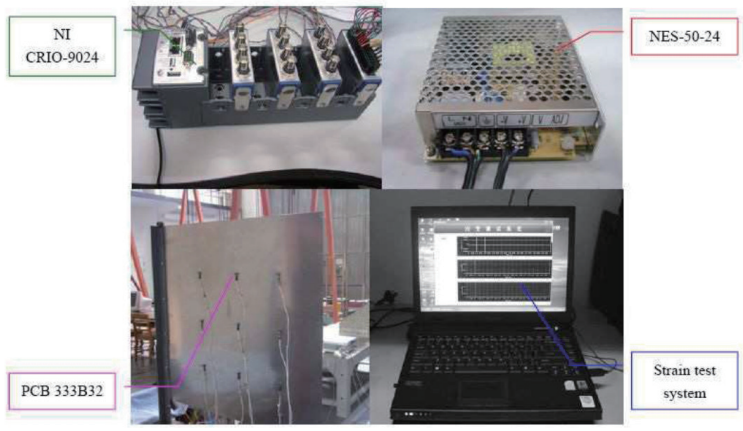

Fig. 9. Experiment and control instruments (2)

Table 4. Experiment test values of strain range shown in Tables 4-10.

To establish the vibration control model, in this section, experimental tests of the plate are used to determine parameters of the model. The reason for using an experiment for the input matrix $\mathrm{L}$, instead of the finite element method (FEM) is because the base displacement of the controlled system can easily reflect the real situation of an intelligent vibration control system. This would make the control system (Figs. 8, 9) for vibration more effective. Moreover, the other system parametric values as presented in Tables 6-10.

\section{Establish the experimental system}

The experimental test results are shown in Figures 11-15. Some experiments must be performed if the ASM MIMO

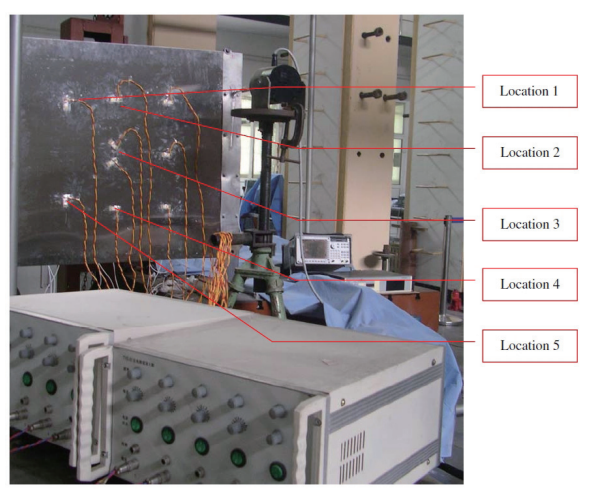

Fig. 10. Five locations of PZT

\begin{tabular}{|c|c|c|c|c|c|c|c|c|c|c|}
\hline \multicolumn{11}{|c|}{ Location } \\
\hline & & 1 & 2 & 3 & 4 & 5 & 6 & 7 & 8 & 9 \\
\hline \multirow{4}{*}{ Static } & Group 1 & 995 & 977 & 131 & 140 & 131 & 968 & 131 & 140 & 1012 \\
\hline & Group 2 & 986 & 968 & 140 & 123 & 140 & 986 & 123 & 149 & 995 \\
\hline & Group 3 & 977 & 977 & 123 & 131 & 123 & 997 & 114 & 131 & 1004 \\
\hline & Average & 986 & 974 & 131 & 137 & 137 & 983 & 123 & 140 & 1003 \\
\hline \multirow{4}{*}{ Deformed } & Group 1 & 995 & 986 & 123 & 131 & 105 & 123 & 123 & 123 & 986 \\
\hline & Group 2 & 986 & 1012 & 114 & 114 & 114 & 114 & 114 & 114 & 995 \\
\hline & Group 3 & 977 & 995 & 131 & 123 & 131 & 105 & 140 & 131 & 977 \\
\hline & Average & 986 & 992 & 123 & 123 & 117 & 114 & 126 & 123 & 986 \\
\hline & & 0 & 18 & -8 & -14 & -20 & & 3 & -17 & -17 \\
\hline
\end{tabular}


control design is to be accepted by people in the research field. From the experimental set-up photograph in Figure 8, a steel cantilever plate bonded with nine piezoelectric actuators is shown. Moreover, near the fixed end, a PCB sensor is used to acquire the displacement of flexible plate. Then, the acquired displacement signal is transmitted to the NI data acquisition (DAQ). Next, the NI compactrio is used to process experiment data and generate the actuating control voltage signals for piezoelectric patches to actuate the cantilevered plate. The computer loads the LABVIEW control programs to the NI compactrio and achieves current collect, process, store, and display of experimental data. Finally, the experimental results above are presented to confirm the capacity of the intelligent vibration controller. Additionally, in the experiments, two different control schemes are presented to confirm the effectiveness of the intelligent control system described. The validity of vibration suppression with the ASM MIMO was tested effectively.

Table 5. Model test value of natural frequency after installed actuators and sensors

\begin{tabular}{|l|l|l|l|l|l|l|l|l|l|l|}
\hline \multicolumn{1}{|l|}{ Frequency } \\
\hline Location & Type & 1 & 2 & 3 & 4 & 5 & 6 & 7 & 8 & 9 \\
\hline A & $\begin{array}{l}\text { Sine } \\
\text { Sweep }\end{array}$ & 0.68 & 2.72 & 3.91 & 6.54 & 7.14 & 10.40 & 13.03 & 14.96 & 17.17 \\
\hline B & $\begin{array}{l}\text { Sine } \\
\text { Sweep }\end{array}$ & 0.67 & 2.75 & 3.86 & 6.54 & 7.14 & 10.53 & 13.03 & 14.96 & 17.17 \\
\hline Average & 0.675 & 2.735 & 3.885 & 6.54 & 7.14 & 10.465 & 13.03 & 14.96 & 17.17 \\
\hline
\end{tabular}

Table 6. Experimental test values of displacement and voltages

\begin{tabular}{|c|c|c|c|c|c|c|c|c|c|c|c|c|c|c|c|c|}
\hline \multicolumn{17}{|c|}{ Voltage (V) } \\
\hline \multirow{2}{*}{\multicolumn{2}{|c|}{$\mathrm{CM}$}} & $\begin{array}{l}0 \\
\times\end{array}$ & $\begin{array}{l}4 \\
\times\end{array}$ & $\begin{array}{r}4 \\
\times\end{array}$ & $\begin{array}{l}6 \\
\times\end{array}$ & $\begin{array}{l}5 \\
\times\end{array}$ & $\begin{array}{l}9 \\
\times\end{array}$ & $\begin{array}{l}6 \\
\times\end{array}$ & $\begin{array}{l}9 \\
\times\end{array}$ & $\begin{array}{l}8 \\
\times\end{array}$ & $\begin{array}{l}7 \\
\times\end{array}$ & $\begin{array}{l}9 \\
\times\end{array}$ & $\begin{array}{c}10 \\
\times\end{array}$ & $\begin{array}{c}10 \\
\times\end{array}$ & $\begin{array}{l}9 \\
\times\end{array}$ & $\begin{array}{l}9 \\
\times\end{array}$ \\
\hline & & 0 & 8 & 10 & 8 & 10 & 6 & 10 & 7 & 8 & 10 & 8 & 8 & 8 & 9 & 10 \\
\hline \multirow{9}{*}{$\begin{array}{c}\mathrm{C} \\
\mathrm{O} \\
\mathrm{L} \\
\mathrm{U} \\
\mathrm{M} \\
\mathrm{N}\end{array}$} & 1 & 0 & -1.5 & -2.1 & -2 & -2 & -1 & -2 & -0.5 & -1.9 & -2.2 & -2 & -2 & -2 & -2.5 & -1.9 \\
\hline & 2 & 0 & -0.5 & -0.8 & -0.5 & -0.5 & -0.5 & -0.5 & -1 & -0.2 & -1.2 & -1.5 & -0.5 & -0.9 & 0 & -1 \\
\hline & 3 & 0 & -1 & -0.7 & -0.8 & -1 & 0 & -0.7 & -1.2 & -1 & -1 & -1.1 & -1.2 & -1.2 & -1 & -1 \\
\hline & 4 & 0 & 3 & 2.8 & 2.5 & 3 & 1.5 & 2.8 & 2 & 2.8 & 2.5 & 2.5 & 3.5 & 2 & 2.5 & 3 \\
\hline & 5 & 0 & 2.5 & 2.2 & 2 & 2 & 1 & 1.2 & 1.3 & 2.5 & 1.5 & 2.5 & 2 & 2.3 & 2 & 2.2 \\
\hline & 6 & 0 & 2.3 & 1.7 & 2.5 & 2.4 & 1.5 & 2.3 & 1.3 & 2.3 & 2 & 2 & 1 & 2.3 & 1.3 & 1.6 \\
\hline & 7 & 0 & -0.45 & -0.5 & -0.55 & -0.45 & -0.25 & -0.45 & -0.27 & -0.57 & -0.45 & -0.25 & -0.58 & -0.32 & -0.27 & -0.28 \\
\hline & 8 & 0 & -0.55 & -0.35 & -0.4 & -0.17 & -0.05 & -0.27 & -0.17 & -0.37 & -0.25 & -0.15 & -0.4 & -0.23 & -0.2 & -0.25 \\
\hline & 9 & 0 & 2.8 & 2.5 & 2.5 & 2.2 & 2 & 3 & 2.1 & 2.8 & 2.1 & 2.5 & 2 & 2.3 & 2 & 2.1 \\
\hline
\end{tabular}

Table 7. Experimental test values of input matrix $L$

\begin{tabular}{|c|c|c|c|c|c|c|c|c|c|c|}
\hline & \multicolumn{9}{|l|}{ Row } \\
\hline & & 1 & 2 & 3 & 4 & 5 & 6 & 7 & 8 & 9 \\
\hline \multirow{9}{*}{$\mathrm{C}$} & 1 & 0.000189 & 0.00016 & 0.00021 & 0.00022 & 0.00020 & 0.00020 & 0.00016 & 0.00020 & 0.00018 \\
\hline & 2 & 0.000237 & 0.00020 & 0.00026 & 0.000286 & 0.00026 & 0.00025 & 0.000204 & 0.000251 & 0.000232 \\
\hline & 3 & 0.00028 & 0.00024 & 0.00031 & 0.00034 & 0.00031 & 0.00031 & 0.000245 & 0.000301 & 0.000279 \\
\hline & 4 & 0.000355 & 0.00030 & 0.000398 & 0.000429 & 0.00039 & 0.000388 & 0.000306 & 0.000377 & 0.000349 \\
\hline & 5 & 0.00037 & 0.00032 & 0.00042 & 0.00045 & 0.00041 & 0.000414 & 0.000326 & 0.000402 & 0.000372 \\
\hline & 6 & 0.00041 & 0.00035 & 0.00046 & 0.0005 & 0.00045 & 0.00045 & 0.00035 & 0.00044 & 0.00040 \\
\hline & 7 & 0.00047 & 0.00040 & 0.00053 & 0.00057 & 0.00052 & 0.00051 & 0.00040 & 0.00050 & 0.00046 \\
\hline & 8 & 0.00048 & 0.00041 & 0.00053 & 0.00057 & 0.00052 & 0.00052 & 0.00041 & 0.00050 & 0.00047 \\
\hline & 9 & 0.00053 & 0.00045 & 0.00059 & 0.00064 & 0.00058 & 0.00058 & 0.00045 & 0.00056 & 0.00052 \\
\hline
\end{tabular}




\section{Conclusions}

In this paper, we studied the vibration tracking control problem of a flexible plate structure system and proposed an ASM MIMO control method. ASM MIMO control is a combination of adaptive control and sliding mode control, having the advantages of intelligent control, MIMO control, and non-linear control in the sense of robustness of the control system. The proposed sliding mode control law is an intelligent feedback control law that involves tracking positions and tracking velocities. One advantage of the proposed ASM MIMO controller is that it is a MIMO control law that differs from a SISO controller; it can be used to deal with a complex system with features of non linearity and parameter coupling. The robust design of the ASM MIMO control is another advantage compared with a conventional PD control method. Simulation results demonstrated that

Table 8. Experimental test values of mass matrix $M$

\begin{tabular}{|c|c|c|c|c|c|c|c|c|c|c|}
\hline & \multicolumn{9}{|c|}{ Row } \\
\hline & & 1 & 2 & 3 & 4 & 5 & 6 & 7 & 8 & 9 \\
\hline \multirow{9}{*}{$\begin{array}{l}\mathrm{C} \\
\mathrm{O} \\
\mathrm{L} \\
\mathrm{U} \\
\mathrm{M} \\
\mathrm{N}\end{array}$} & 1 & 0.88 & 0 & 0 & 0 & 0 & 0 & 0 & 0 & 0 \\
\hline & 2 & 0 & 0.88 & 0 & 0 & 0 & 0 & 0 & 0 & 0 \\
\hline & 3 & 0 & 0 & 0.88 & 0 & 0 & 0 & 0 & 0 & 0 \\
\hline & 4 & 0 & 0 & 0 & 0.88 & 0 & 0 & 0 & 0 & 0 \\
\hline & 5 & 0 & 0 & 0 & 0 & 0.88 & 0 & 0 & 0 & 0 \\
\hline & 6 & 0 & 0 & 0 & 0 & 0 & 0.88 & 0 & 0 & 0 \\
\hline & 7 & 0 & 0 & 0 & 0 & 0 & 0 & 0.88 & 0 & 0 \\
\hline & 8 & 0 & 0 & 0 & 0 & 0 & 0 & 0 & 0.88 & 0 \\
\hline & 9 & 0 & 0 & 0 & 0 & 0 & 0 & 0 & 0 & 0.88 \\
\hline
\end{tabular}

Table 9. Stiffness matrix K value

\begin{tabular}{|c|c|c|c|c|c|c|c|c|c|c|}
\hline \multicolumn{2}{|c|}{$\mathrm{N} / \mathrm{M}$} & \multicolumn{10}{|c|}{ Row } \\
\cline { 2 - 12 } & 1 & 2 & 3 & 4 & 5 & 6 & 7 & 8 & 9 \\
\hline \multirow{4}{*}{$\mathrm{C}$} & 1 & 202.7 & -67.6 & 0 & -67.6 & 0 & 0 & 0 & 0 & 0 \\
\cline { 2 - 12 } $\mathrm{O}$ & 2 & -218.2 & 654.6 & -218.2 & 0 & -218.2 & 0 & 0 & 0 & 0 \\
\cline { 2 - 12 } $\mathrm{O}$ & 3 & 0 & -10.4 & 20.8 & 0 & 0 & -10.4 & 0 & 0 & 0 \\
\cline { 2 - 12 } $\mathrm{L}$ & 4 & -262.5 & 0 & 0 & 1050 & -262.5 & 0 & -262.5 & 0 & 0 \\
\cline { 2 - 12 } $\mathrm{U}$ & 5 & 0 & -138.1 & 0 & -138.1 & 552.4 & -138.1 & 0 & -138.1 & 0 \\
\cline { 2 - 12 } $\mathrm{M}$ & 6 & 0 & 0 & -282.2 & 0 & -282.2 & 846.6 & 0 & 0 & -282.2 \\
\cline { 2 - 11 } $\mathrm{N}$ & 7 & 0 & 0 & 0 & -67.6 & 0 & 0 & 202.7 & -67.6 & 0 \\
\cline { 2 - 11 } & 8 & 0 & 0 & 0 & 0 & -218.2 & 0 & -218.2 & 654.6 & -218.2 \\
\cline { 2 - 11 } & 9 & 0 & 0 & 0 & 0 & 0 & -10.4 & 0 & -10.4 & 20.8 \\
\hline
\end{tabular}

Table 10. Damping matrix c value

\begin{tabular}{|c|c|c|c|c|c|c|c|c|c|c|}
\hline \multirow{2}{*}{\multicolumn{2}{|c|}{$\begin{array}{c}\mathrm{N} \cdot \mathrm{S} / \\
\mathrm{M}\end{array}$}} & \multicolumn{9}{|c|}{ Row } \\
\hline & & 1 & 2 & 3 & 4 & 5 & 6 & 7 & 8 & 9 \\
\hline \multirow{9}{*}{$\begin{array}{l}\mathrm{C} \\
\mathrm{O} \\
\mathrm{L} \\
\mathrm{U} \\
\mathrm{M} \\
\mathrm{N}\end{array}$} & 1 & 202.7 & -67.6 & 0 & -67.6 & 0 & 0 & 0 & 0 & 0 \\
\hline & 2 & -218.2 & 654.6 & -218.2 & 0 & -218.2 & 0 & 0 & 0 & 0 \\
\hline & 3 & 0 & -10.4 & 20.8 & 0 & 0 & -10.4 & 0 & 0 & 0 \\
\hline & 4 & -262.5 & 0 & 0 & 1050 & -262.5 & 0 & -262.5 & 0 & 0 \\
\hline & 5 & 0 & -138.1 & 0 & -138.1 & 552.4 & -138.1 & 0 & -138.1 & 0 \\
\hline & 6 & 0 & 0 & -282.2 & 0 & -282.2 & 846.6 & 0 & 0 & -282.2 \\
\hline & 7 & 0 & 0 & 0 & -67.6 & 0 & 0 & 202.7 & -67.6 & 0 \\
\hline & 8 & 0 & 0 & 0 & 0 & -218.2 & 0 & -218.2 & 654.6 & -218.2 \\
\hline & 9 & 0 & 0 & 0 & 0 & 0 & -10.4 & 0 & -10.4 & 20.8 \\
\hline
\end{tabular}




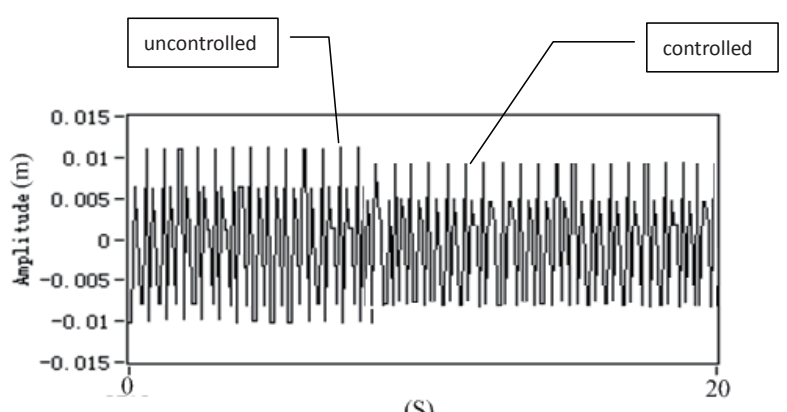

Fig. 11. Location 1's forced vibration response (controlled with $10 \mathrm{~V}$ voltage)

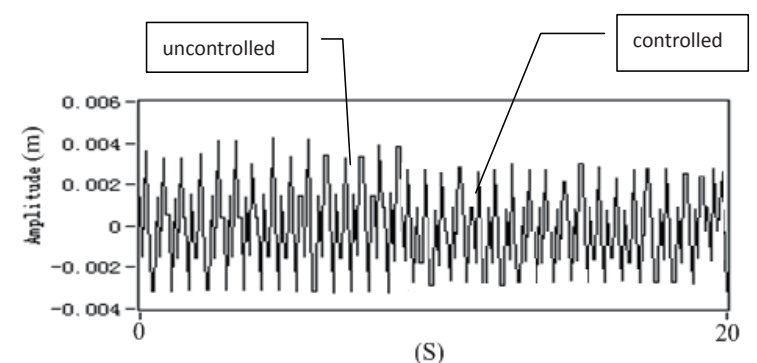

Fig. 13. Location 3's forced vibration response (controlled with $20 \mathrm{~V}$ voltage)

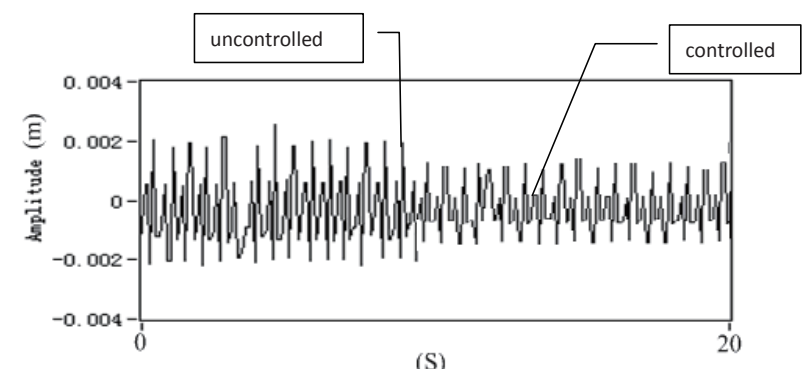

(S)

Fig. 15. Forced vibration response of Location 5 (controlled with $20 \mathrm{~V}$ voltage)

ASM MIMO control is superior to PD in terms of good vibration tracking control performance under external disturbances, parametric uncertainties, and varying load conditions.

\section{Acknowledgments}

This work was supported by the project "Research on Intelligent Integrated Control of Coupling between Space Solar Power Station Structure Vibration and Attitude Control" (BYB22) and "Exploration and Practice of 'Theory + Interesting +Research' Innovative Teaching Mode" (YJS201411).

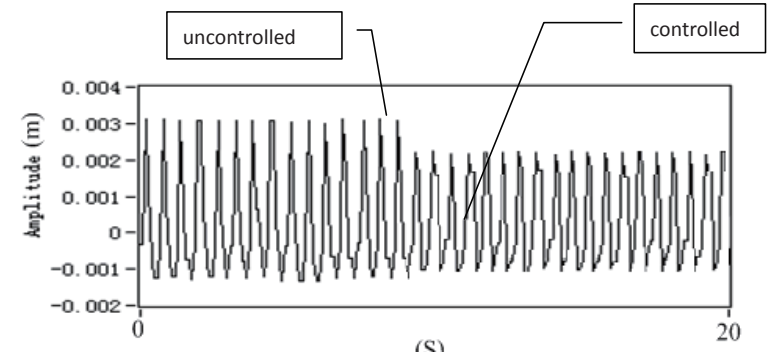

Fig. 12. Location 2's forced vibration response of (controlled with $20 \mathrm{~V}$ voltage)

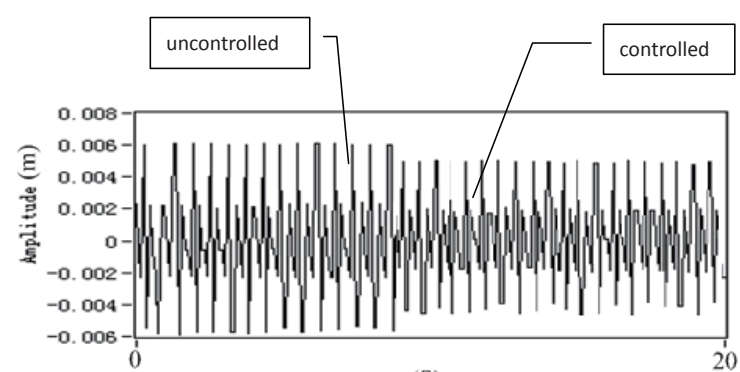

(S)

Fig. 14. Location 4's forced vibration response (controlled with $10 \mathrm{~V}$ voltage)

\section{References}

[1] Yang D. and Zhou J., "Commun Nonlinear Sci Numer Simulat Connections among several chaos feedback control approaches and chaotic vibration control of mechanical systems", Communications in Nonlinear Science and Numerical Simulation, Vol. 19, No. 11, 2014, pp. 3954-3968.

[2] Zhou D. Li J. and Zhang K., Amplitude control of the track-induced self-excited vibration for a maglev system. ISA transactions. 2014 Jan;p.1-7.

[3] You BD., Wen JM. and Zhao Y., "Nonlinear analysis and vibration suppression control for a rigid-flexible coupling satellite antenna system composed of laminated shell reflector", Acta Astronautica, Vol. 96, 2014, pp. 269-279.

[4] Previdi F., Spelta C., Madaschi M., Belloli D., Savaresi SM. and Faginoli F, et al., "Active vibration control over the flexible structure of a kitchen hood", Mechatronics, Vol. 24, No. 3, 2014, pp. 198-208.

[5] Sun X., Xu J., Jing X. and Cheng L., "Beneficial performance of a quasi-zero-stiffness vibration isolator with time-delayed active control", International Journal of Mechanical Sciences, Vol. 82, 2014, pp. 32-40.

[6] Wu D., Huang L., Pan B., Wang Y. and Wu S., "Experimental study and numerical simulation of active vibration control of a highly flexible beam using piezoelectric 
intelligent material", Aerospace Science and Technolog, Vol. 37, 2014, pp. 10-19.

[7] Cazzulani G.., Cinquemani S., Comolli L., Gardella A. and Resta F.. "Vibration control of smart structures using an array of Fiber Bragg Grating sensors", Mechatronics. Vol. 24, No. 4, 2014, pp. 345-353.

[8] Quan Hu. and Yinghong Jia SX., "Dynamics and vibration suppression of space structures with control moment gyroscopes", Acta Astronautica journal, Vol. 96, 2014, pp. 232-245.

[9] Ma X., Jin G. and Liu Z., "Active structural acoustic control of an elastic cylindrical shell coupled to a twostage vibration isolation system", International Journal of Mechanical Sciences, Vol. 79, 2014, pp. 182-194.

[10] Zhang H., "Robust finite frequency H 1 static-outputfeedback control with application to vibration active control of structural systems", Mechatronics, Vol. 24, No. 4, 2014, pp. 354-366.

[11] Qiu Z. and Ling D., "Finite element modeling and robust vibration control of two-hinged plate using bonded piezoelectric sensors and actuators", Acta Mechanica Solida Sinica, Vol. 27, No. 2, 2014, pp. 146-161.

[12] Zolfagharian A., Noshadi A., Khosravani MR. and Zain MZM., "Unwanted noise and vibration control using finite element analysis and artificial intelligence", Applied Mathematical Modelling, Vol. 38, No. 9-10, 2014, pp. 2435-2453.

[13] Smoczek J., "Fuzzy crane control with sensorless payload deflection feedback for vibration reduction", Mechanical Systems and Signal Processing, Vol. 46, No. 1, 2014, pp. 70-81.

[14] Zori'c ND., Simonovi'c AM., Mitrovi'c ZS., Stupar SN., Obradovi'c AM. and Luki'c NS., "Free vibration control of smart composite beams using particle swarm optimized self-tuning fuzzy logic controller", Journal of Sound and Vibration, Vol. 333, 2014, pp. 5244-5268.

[15] M aEK., Uchiyama N. and Sano S., "Sliding Mode Contouring Control for Biaxial Feed Drive Systems with a Nonlinear Sliding Surface", Procedia CIRP, Vol. 14, 2014, pp. 506-510.

[16] Oliveira JB., Boaventura-Cunha J., Moura Oliveira PB. and Freire H., "A swarm intelligence-based tuning method for the sliding mode generalized predictive control", ISA transactions, 2014, pp. 1-15.
[17] Chen F., Jiang B. and Tao G., "An intelligent selfrepairing control for nonlinear MIMO systems via adaptive sliding mode control technology", Journal of the Franklin Institute, Vol. 351, No. 1. 2014, pp. 399-411.

[18] Ghasemi M. and Nersesov SG., "Finite-time coordination in multiagent systems using sliding mode control approach", Automatica, Vol. 50, No. 4, 2014, pp. 1209-1216.

[19] Acosta P., "Natural surface design for sliding mode control with multiple discontinuous inputs", Journal of the Franklin Institute, Vol. 351, No. 8, 2014, pp. 4198-4210.

[20] Zhang B., Pi Y. and Luo Y., "Fractional order slidingmode control based on parameters auto-tuning for velocity control of permanent magnet synchronous motor", ISA transactions, Vol. 51, No. 5, 2012, pp. 649-656.

[21] Zhang H., Wang J. and Shi Y., "Robust sliding-mode control for Markovian jump systems subject to intermittent observations and partially known transition probabilities", Systems and Control Letters, Vol. 62, No. 12, 2013, pp. 1114 $-1124$.

[22] Yang J. and Chen G., "Experiment Study of Adaptive Fuzzy Sliding Mode Control for Vibration of Flexible Rectangular Plate", Journal of Aerospace Engineering, 2014..

[23] Jingyu Y. and Guoping C., "Adaptive iterative learning control for vibration of flexural rectangular plate", Mechanika, Vol. 15, No. 7, 2011, pp. 485-491.

[24] Guo Y. and Woo PY., "An adaptive fuzzy sliding mode controller for robotic manipulators", Systems, Man and Cybernetics, Part A: Systems and Humans, IEEE Transactions, Vol. 33, No. 2, 2003, pp. 149-159.

[25] E SJ., "On the Adaptive Control of Robot Manipulators", The International Journal of Robotics Research, Vol. 6, No. 3, 1987, pp. 49-59.

[26] Craig J., Introduction to robotics: mechanics and control, 2005.

[27] Jingyu Y. and Guoping C., "Orientations and locations optimization of actuators and sensors for structural shape control", Advanced Science Letters, Vol. 6, 2012, pp. 547-552.

[28] Jingyu Y. and Guoping C., "Multi-Objective Optimization of Orientations and Locations of Actuators and Sensors for Structural Shape Control", Advanced Science Letters, Vol. 6, 2012, pp. 511-517. 